\title{
New Research Progress Review on Psychological Ownership
}

\author{
Xie Qian \\ Department of Business Management, School of Management, Jinan University, Guangzhou, China \\ Email: 260463246@qq.com
}

Received 24 March 2016; accepted 22 April 2016; published 27 April 2016

Copyright (C) 2016 by author and Scientific Research Publishing Inc. This work is licensed under the Creative Commons Attribution International License (CC BY). http://creativecommons.org/licenses/by/4.0/

c) (i) Open Access

\begin{abstract}
This paper reviews the latest research on psychological ownership from the following three aspects: 1) theoretical background of psychological ownership; 2) connotation and measurement of psychological ownership; 3) formation mechanism and influence mechanism of psychological ownership. This paper also reveals the formation mechanism, the impact mechanism and interpretation of psychological ownership from local organization members' perspective under Chinese culture.
\end{abstract}

Keywords

Psychological Ownership, Formal Ownership, Local Enterprises

\section{Introduction}

The roots of the Psychological Ownership Theory can be traced back to the elaboration of "me” and "my stuff” from James. James thinks that a person's self is the sum of his belongings. If the belongings become rich or prosperity, the person will feel successful; if these things shrunk or even die, he will feel frustrated. Based on this, Pierce et al. [1] defined the concept of psychological ownership and emphasized that the person regarded his belongings as their own, so this indicates that the individual who has psychological ownership will regard his belongings as his extension. It is also worth emphasizing that the self-concept and self-extending is the product of cultural values. It will be learned in the process of socialization and influenced by the social culture. For example, Furby [2] believes that cultural awareness and personal values shape someone's ideas about what can be occupied and what cannot be occupied. Pierce et al. [1] also found that psychological ownership concentrated on the individual level under individualistic cultural and collective psychological ownership more emphasized on group level under collective cultural background. But the concept of collective psychological ownership has not yet been fully studied and explored. Moreover, the meaning of psychological ownership may be different and 
vary from different belongings which induce psychological ownership. So the diversity of psychological ownership will have some inspiration on the understanding of power struggle between group members. There are two kinds of psychological ownership between group members. One is resulted from economic gains from equity ownership. The other is resulted from the relationship between each other that caused by blood contact or long time coexistence. Such as family business owners will have psychological ownership caused by the relationship between family members who participated in business activities. If the sense of psychological ownership caused by economic gains is more intense than the psychological ownership caused by relationship, then in some cases there will induce internal conflict between family members, and in other cases family members will compromise to gains from equity. This respective can also applied to analyze relational governance between entrepreneurs and managers. But this has not been developed deeply in theoretical research.

\section{Progress in the Study of Psychological Ownership's Formation}

The motivation to acquire psychological ownership resulted from three aspects: self-efficacy, self-identity and space to hold. Researchers found that these three aspects of motivation had a significant positive correlation with psychological ownership. However, the meaning and impact of these three motives will differ in different cultural. Pierce et al. suggested that the self-identification motive (self-identity revealed to others) will be more important under the collective culture. And Yang Guoshu [3] found that self-identification may not be a strong motivation for the Chinese. Chinese people think that a civilized man cannot be overemphasized and self-disclosure, because this may break social relationship. Recently, the studies from Li Rui et al. [4] showed that the stronger employees collectivism values, the higher level of psychological ownership.

Research on the formation mechanism of psychological ownership can be divided into two paths: one path is from the perspective of formal ownership, emphasizing the acquisition of information rights, property rights and control can generate psychological ownership; the other path is from the perspective of organizational situational factors, emphasizing job design, job technical characteristics, leadership and other factors that could contribute to the formation of psychological ownership.

\subsection{The Impact on Psychological Ownership from Formal Ownership}

Pierce et al. pointed out that employees' formal ownership (including the rights to hold enterprise equity, the rights to obtain business information and control enterprises) had mediating effect on employee behavior and attitudes through psychological ownership.

Early in the research of psychological ownership, researchers had noted the formal ownership (a multi-dimensional concept, including property rights, control rights and the right to information), but until Li et al. developed a three-dimensional scale of formal ownership, and validated its mediating effect on work performance through psychological ownership, researchers had laid operational definition of formal ownership and conducted quantitative research on it. Thereafter, Pierce and Rogers [5] further improved the impact path of formal ownership. They suggested that employees obtain formal ownership has the feeling of owning businesses, while this objective and subjective ownership will make employees realize that they are important and valuable in the organization, thereby employees would have high organizational self-esteem. According to the theory of self-consistency, maintaining high self-evaluation becomes a kind of self-motivation, and employees strive for a higher job performance to maintain good self-evaluation driven by this incentive. Then some researchers proposed new ideas about formal ownership and psychological ownership association mechanism, such as Chi and Han [6] indicated that formal ownership had mediating effect on psychological ownership through organizational justice. Specifically, property rights had mediating effect on psychological ownership through distributive justice, and control rights plus right to information had mediating effect on psychological ownership through procedural fairness. In addition, Bao Shengxiang [7] also discovered the existence of property rights and control rights included in formal ownership had significant mediating effect on psychological ownership in local enterprises.

With the constant change of ownership, the state of Chinese employees' psychological ownership has attracted attention from international scholars. Chui had pointed out that in the process of reforming ownership, formal ownership would have effect on employee attitudes and behavior through psychological ownership in China. In the follow-up study, Chui et al. [8] found that ESOP had significant positive correlation with psychological ownership, and staff job satisfaction had fully mediating effect between ESOP and psychological ownership. Inspired by these studies is that, in local enterprises the return on equity, business information and deci- 
sion authority are all controlled by core family members, so formal ownership isn’t configured according to the official status of members in the organization, but according to "insiders" or "outsiders". It is worthy of further exploration on the impact on the state of employee psychological ownership from the differential allocation pattern of formal ownership in local enterprises.

\subsection{The Impact on Psychological Ownership from Organizational Context}

According to Strong and Weak Situational Scenarios Theory proposed by Chu Xiaoping and Sheng Qiangfang [9] suggested that organizational context also contribute to the formation of psychological ownership. In strong scenario (highly structured background), employee behavior will be constrained and assimilation, preventing the differences of individual expression, but in weak situation, self-definition and self-expression is relatively relaxed. Study on this theory Pierce et al. [10] proposed that psychological ownership comes from technical requirements, work independence and the degree of participation in decision-making. They believe that low level structured work environment (low technical routine, the higher the degree of work autonomy and participation in decision-making) was positively correlated with psychological ownership, and employee work dependence had mediating effect between work environment and psychological ownership. Thereafter, Pierce et al. constructed a model based on the influence of core features, noted that the diversity of skills, task identity, task significance, work autonomy and feedback make an impact on employees' work attitudes and behaviors through psychological ownership. Recently empirical study of local enterprises from Liu et al. [4] found that the atmosphere of self-management team had positive effect on psychological ownership.

It is worth noting that, segregation of duties in local enterprise always creates a job in order to accommodate a person, differed from clear division of duties and standardized job descriptions in Western management. Also in Chinese enterprises, business owners decided specific work permissions, information and benefits distribution according to relationship intimacy. Thus, the relationship with the senior leaders is an important regulator variable in considering the impact on psychological ownership from work design and feather of Chinese business managers. Specifically, even have the same job title and do the same job, managers who have higher relationship with business owner or senior leaders will obtain more authorization information and assets, also stronger psychological ownership. For example, Guo Liang et al. [11] studies showed that in local enterprises LeaderMember Exchange and employee gratitude would bring stronger psychological ownership. Avey et al. [12] found that ethical leadership can enhance psychological ownership and further affected employee work satisfaction. And Li Rui et al. [4] found that in local enterprises authoritarian leadership had negative correlation with psychological ownership. In recent years, more and more studies explored the impact on psychological ownership from leadership.

\section{Progress in the Study of the Effect of Psychological Ownership}

Psychological ownership has incentive effect on employee, because it can meet employees' motive to pursuit self efficacy, self-identification and space owned [5]. Recently, researchers have attempted to study the effects of psychological ownership from other sources differed from self-concept. Liu et al. [4] found that the degree of integration of employees with the company's wealth had positive correlation with psychological ownership base on empirical study of Taiwan companies. Also they found that psychological ownership had partial mediating effect between the degree of integration of wealth (personal and corporate wealth contact), risk appetite and preference for ownership (ownership tendency). Based on Social Exchange Theory, Avey et al. [12] suggested that employment relationship based on social exchange had positive correlation with psychological ownership, and psychological ownership had mediating effect between employment relationship based on social exchange and staff interpersonal cooperation. And Han et al. [9] found psychological ownership stimulated employee knowledge sharing behavior through organizational commitment mediating effect in Taiwan companies. Wang et al. study found that there is a positive correlation between the psychological ownership of professional managers in family business and manager voice behavior.

In contrast, less study concentrated on negative impact on psychological ownership. These negative behaviors may include resistance to change as well as territorial behavior. Brown et al. [13] pointed out that psychological ownership and territories behavior has a positive correlation, it is because motivations including self-identity, self-efficacy and space to hold stimulated oneself to mark, protect and defense for his belonging.

As mentioned before, in Western culture individual tend to express and show differences and Chinese under 
collective culture don't like to exposure self-identity, they emphasis on group identity consistency, in order to maintain community harmony.

\section{Progress in the Study of the Connotation, Object and Measurement of Psychological Ownership}

The researchers have pointed out that psychological ownership is a multi-dimension concept so different objects have different psychological ownership. Follow this thought, multi-dimensional concept and scale of psychological ownership has been developed, and the concept and scale of psychological ownership of different objects been developed.

\subsection{Dimensions of Psychological Ownership}

Based on Constraint focus theory, Avey et al. [12] proposed that psychological ownership (self-made) is divided into two levels: promoted and restrictive. According to the root cause of psychological ownership, Pierce [3] suggested that promoted psychological ownership is further divided into four dimensions: self-efficacy, sense of belonging, a sense of responsibility, self-identity; while restrictive psychological ownership has only a single dimension: territory. On the basis of the theory construction, Avey et al. [12] developed a relevant scale; confirmatory factor analysis confirmed the promotion of the four dimensions of psychological ownership constructs.

\subsection{Psychological Ownership of Different Objects}

As mentioned before, individuals can target many different objects to cause psychological ownership through understanding secret information, self-investment, as well as the control of objects. Mayhew et al. [14] presented the psychological ownership of work mainly refers to the individual perception of the ownership of particular work. They verified the reliability and validity of psychological ownership of the work, meanwhile empirical study results showed that work psychological ownership positively correlated with job satisfaction and work psychological ownership had partially mediating effect between job autonomy and job satisfaction. However, the study also showed that the relationship between job performance and no matter psychological ownership or work psychological ownership is not significant, and the relationship between no matter psychological ownership or work psychological ownership and extra-role behaviors is not significant either. Similar to this, Zhang Hui et al. [15] proposed the concept of brand psychological ownership, refers to employees' psychological state of ownership caused by the company brand (or service brand), and describes the degree that employee regard organization's service brand as their own brand. More empirical study results show that the brand psychological ownership will positively affect outcome variables including brand passionate and brand citizenship behavior. Researchers in the field of marketing believe that customers will have sense of psychological ownership caused by services provide by hospitals, hotels and others. Factors that affect customers' psychological ownership including the degree of personal control, customer participation, sense of belonging and customer acceptance of the company. The outcome of the psychological ownership is higher willingness to pay, word of mouth and to maintain the relationship, and higher willingness to resistant competitive services (products).

\section{Prospect of Psychology Ownership Study}

\subsection{The Concept and Measurement of Psychological Ownership}

The object and its measurement of psychological ownership can be expanded from the following two aspects in China localization studies. Firstly, in local companies organization members may have sense of psychological ownership caused by both dominant formal ownership and the implicit social capital. Business owners in local enterprises depend on a trust relationship between family members and pan family members to obtain management resources. They are able to control and coordinate these social capitals, get information for such capital, and also devote their efforts to appreciate these capitals. Secondly, it is worthy studying the different perception of psychological ownership from different individuals for the same object. If employees in family enterprise are divided into internal group and external group and measure their perception of ownership, there may be some differences. Finally, the family business entrepreneurs and professional managers who both have the sense of 
psychological ownership of the same object may have a greater difference, if they develop consistent perception of psychological ownership caused by new business results, then they may prone to integration, otherwise there will arise conflicts.

\subsection{Formation Mechanism of Psychological Ownership Expanded in Chinese Culture}

The factors that affect the formation of psychological ownership are not only formal ownership and job characteristics but also other organizational factors, such as organizational culture and atmosphere, the attitude of senior managers, the company's goals and vision, the organization's reputation and the company's policies, procedures, etc. are all examined variables that affect psychological ownership [8]. According to the principles of cultural focus, job embedded understand as the network to retain employee in Chinese culture of collectivism would affect manager's psychological ownership.

\subsection{Boundary Conditions of Psychological Ownership Impact}

Pierce et al. [5] proposed Psychological Ownership Model, they pointed out that formal ownership impact on psychological ownership mediated by staff perceived legitimacy of possessed objects, ownership expectations and ownership sources. However, researchers haven't paid enough attention to the boundary conditions of these effects. In future studies, researchers need to focus on the influence of perceived legitimacy of ownership. Since ancient times for the lack of legal provisions of civil law, citizens often lack of effective protection of private property rights, violations of private property rights always happen, so citizens appear the attitude of envying and hating the rich. In the process of social transformation in contemporary China, many unsuitable enrichment situations further aggravated this attitude. In addition, 30 years of Chinese planned economic system of public ownership and corresponding ideology had a profound impact on people's idea of ownership and the concept of wealth. This influence is reflected in: people don't respect private property rights and interests enough; the recognition of property rights trading rules is not high; the perception of wealth psychological ownership arising from using their own property (especially human capital) is difficult to have fair criteria. Specific to local enterprises, managers coveted business owners' earnings, hoping to get more business ownership and control. On the one hand it is affected by the degree of recognition of property rights trading rules; on the other hand business owners do not pay attention to the formal ownership incentives, so as to produce managers' strong psychological ownership and weak formal ownership incentive misalignment. If the manager has the legitimacy recognition obtaining the corresponding formal ownership, then the relationship between formal ownership and psychological ownership is relatively strong. If managers do not think it is appropriate behavior to obtain power and wealth from business owners, the relationship between formal ownership and psychological ownership is weak. In other words, the legitimacy perception of ownership plays a mediating role in the relationship between formal ownership and psychological ownership. In short, the impact boundary conditions of psychological ownership, especially what factors affect the mediating role in the relationship between formal ownership and psychological ownership, need further study.

\section{References}

[1] Pierce, J.L., Kostova, T. and Dirks, K.T. (2001) Toward a Theory of Psychological Ownership in Organizations. Academy of Management Review, 26, 298-310.

[2] Furby, S.L. and Campbell, N.A. (2001) Calibrating Images from Different Dates to "Like-Value” Digital Counts. Remote Sensing of Environment, 77, 186-196. http://dx.doi.org/10.1016/S0034-4257(01)00205-X

[3] Yang, G.S. (2004) Psychology and Behavior of Chinese People: A Study of Localization. China Renmin University Press, Beijing.

[4] Li, R., Ling, W.Q. and Liu, S.S. (2012) Antecedents and Consequences of Organizational Psychology Ownership: Based on Human Interaction with Environmental Perspective. Journal of Psychology, 44.

[5] Pierce, J.L. and Rodgers, L. (2004) The Psychology of Ownership and worker-Owner Productivity. Group \& Organization Management, 29, 588-613. http://dx.doi.org/10.1177/1059601103254270

[6] Chi, N.W. and Han, T S. (2010) Exploring the Linkages between Formal Ownership and Psychological Ownership for the Organization: The Mediating Role of Organizational Justice. Journal of Occupational \& Organizational Psychology, 81, 691-711. http://dx.doi.org/10.1348/096317907X262314 
[7] Bao, S.X. (2005) Psychological and Behavioral Changes after Employee Stock Ownership—An Empirical Analysis Based on the Theory of Psychological Ownership. Management Science, 18, 23-27.

[8] Chiu, W.C.K., Hui, C.H. and Lai, G.W.F. (2007) Psychological Ownership and Organizational Optimism amid China’s Corporate Transformation: Effects of an Employee Ownership Scheme and a Management-Dominated Board. International Journal of Human Resource Management, 18, 303-320. http://dx.doi.org/10.1080/09585190601102539

[9] Chu, X.P. and Sheng, Q.F. (2010) Organizational Change, Psychological Ownership and Employee Voluntary Turnover-Discussing the Expand the Model of Employee Turnover Proposed by Lee and Mitchell. Journal of Sun Yat-sen University: Social Science Edition, 50, 156-163.

[10] Pierce, J.L., Jussila, I. and Cummings, A. (2009) Psychological Ownership within the Job Design Context: Revision of the Job Characteristics Model. Journal of Organizational Behavior, 30, 477-496. http://dx.doi.org/10.1002/job.550

[11] Liang, G., Li, X.Y. and Chen, S. (2014) The Impact on Individual Initiative-Leadership from Thanksgiving Which Has Intermediary Effect between LMX and Psychological Ownership. Journal of Management, 11, 1014-1020.

[12] Avey, J.B., Avolio, B.J., Crossley, C.D. and Luthans, F. (2009) Psychological Ownership: Theoretical Extensions Measurement and Relation to Work Outcomes. Journal of Organizational Behavior, 30, 173-191. http://dx.doi.org/10.1002/job.583

[13] Brown, G. and Robinson, S.L. (2005) Territoriality in Organizations. Academy of Management Review, 30, 577-594. http://dx.doi.org/10.5465/AMR.2005.17293710

[14] Mayhew, M.G., Ashkanasy, N.M., Bramble, T. and Gardner, J. (2007) A Study of the Antecedents and Consequences of Psychological Ownership in Organizational Settings. Journal of Social Psychology, 147, 477-500. http://dx.doi.org/10.3200/SOCP.147.5.477-500

[15] Dai, B. and Zhang, H. (2008) The Application of Psychological Contract in Human Resource Management. Market Modernization, No. 33, 315. 